\title{
Computational Fluid Dynamic Simulations of Single-Phase Flow in a Spacer-Filled Channel of a Filter-Press Electrolyzer
}

\author{
Locksley Castañeda ${ }^{1}$, René Antaño ${ }^{1}$, Fernando F. Rivera ${ }^{1}$, José L. Nava ${ }^{2, *}$ \\ ${ }^{1}$ Centro de Investigación y Desarrollo Tecnológico en Electroquímica, Parque Tecnológico Querétaro, \\ Sanfandila, Pedro Escobedo, C.P. 76703 Querétaro, México. \\ ${ }^{2}$ Universidad de Guanajuato, Departamento de Ingeniería Geomática e Hidráulica, Av. Juárez 77, \\ Zona Centro, C.P. 36000, Guanajuato, Guanajuato, Mexico. \\ *E-mail: jlnm@ugto.mx
}

doi: $10.20964 / 2017.08 .09$

Received: 27 March 2017 / Accepted: 19 May 2017 / Published: 12 July 2017

\begin{abstract}
Computational fluid dynamic (CFD) simulations were performed for single-phase flow in a spacerfilled channel of a filter-press electrolyzer solving the Reynolds-averaged Navier-Stokes (RANS) equations with the $k-\varepsilon$ turbulence model. For the first time the physical presence of a turbulence promoter in a pre-pilot scale filter-press electrolyzer was included in the simulation, obtaining excellent agreement of simulations with experimental residence time distribution (RTD) results. CFD simulations evidence that net-like spacer homogenizes the flow distribution, provoking an increase in local Reynolds numbers. Also, the velocity profiles are strongly affected by the flow distributor at the inlet of the electrolyzer, but these become more uniform in the presence of the turbulence promoter.
\end{abstract}

Keywords: Flow hydrodynamics, Filter-press electrolyzer, Turbulence promoter, Turbulent flow

\section{FULL TEXT}

(C) 2017 The Authors. Published by ESG (www.electrochemsci.org). This article is an open access article distributed under the terms and conditions of the Creative Commons Attribution license (http://creativecommons.org/licenses/by/4.0/). 